\title{
The neural correlates of rhyme awareness in preliterate and literate children
}

\author{
Barbara Wagensveld ${ }^{\mathrm{a}, \mathrm{b}, *}$, Petra van Alphen ${ }^{\mathrm{c}, 1}$, Eliane Segers ${ }^{\mathrm{a}}$, Peter Hagoort ${ }^{\mathrm{b}, \mathrm{c}}$, Ludo Verhoeven ${ }^{\mathrm{a}}$ \\ a Behavioural Science Institute, Radboud University, P.O. Box 9104, 6500 HE Nijmegen, The Netherlands \\ ${ }^{\mathrm{b}}$ Donders Institute for Brain, Cognition and Behaviour, Centre for Cognitive Neuroimaging, P.O. Box 9101, 6500 HB Nijmegen, The Netherlands

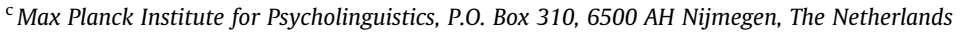

\section{A R T I C L E I N F O}

\section{Article history:}

Accepted 27 January 2013

Available online 19 March 2013

\section{Keywords:}

Phonological awareness

Rhyme

EEG

N450

Children

\section{H I G H L I G H T S}

- Behavioral and electrophysiological responses were recorded while (pre)literate children made rhyme judgments of rhyming, overlapping and unrelated words.

- Behaviorally both groups had difficulty judging overlapping pairs as non-rhyming while overlapping and unrelated neural patterns were similar in literates.

- Preliterates show a different pattern indicating a developing phonological system.

\section{A B S T R A C T}

Objective: Most rhyme awareness assessments do not encompass measures of the global similarity effect (i.e., children who are able to perform simple rhyme judgments get confused when presented with globally similar non-rhyming pairs). The present study examines the neural nature of this effect by studying the N450 rhyme effect.

Methods: Behavioral and electrophysiological responses of Dutch pre-literate kindergartners and literate second graders were recorded while they made rhyme judgments of word pairs in three conditions; phonologically rhyming (e.g., wijn-pijn), overlapping non-rhyming (e.g., pen-pijn) and unrelated nonrhyming pairs (e.g., boom-pijn).

Results: Behaviorally, both groups had difficulty judging overlapping but not rhyming and unrelated pairs. The neural data of second graders showed overlapping pairs were processed in a similar fashion as unrelated pairs; both showed a more negative deflection of the N450 component than rhyming items. Kindergartners did not show a typical N450 rhyme effect. However, some other interesting ERP differences were observed, indicating preliterates are sensitive to rhyme at a certain level.

Significance: Rhyme judgments of globally similar items rely on the same process as rhyme judgments of rhyming and unrelated items. Therefore, incorporating a globally similar condition in rhyme assessments may lead to a more in-depth measure of early phonological awareness skills.

๑) 2013 International Federation of Clinical Neurophysiology. Published by Elsevier Ireland Ltd. All rights

reserved.

\section{Introduction}

Sensitivity to rhyme develops early in life. Infant studies have shown that nine-month-olds already respond to changes in rhyme pattern or even smaller changes within the rhyme constituent of a word (Hayes et al., 2000, 2009). Nonetheless, the ability to consciously attend to phonological information does not develop until the age of three and generally starts with an awareness of

\footnotetext{
* Corresponding author at: Behavioural Science Institute, Radboud University, P.O. Box 9104, 6500 HE Nijmegen, The Netherlands. Tel.: +31 2436 12822; fax: +31 243616211.

E-mail address: b.wagensveld@pwo.ru.nl (B. Wagensveld).

1 Present address: Koninklijke Kentalis, P.O. Box 7, 5270 BA Sint-Michielsgestel, The Netherlands.
}

rhyme (Chard and Dickson, 1999; Vloedgraven and Verhoeven, 2007). Therefore, rhyming tasks are often incorporated in screening measures for the detection of early language and literacy problems in both research and practice. However, these rhyme awareness assessment are often fairly simple in nature and do not encompass more demanding conditions that tap into the more developed levels of rhyme awareness. For example, although it is clear that most children can rhyme prior to the start of formal education, there is evidence that they have not yet fully mastered this skill. Behavioral studies have shown that kindergartners can easily state that bell and ball rhyme, due to the global phonological similarities between these two words (Carroll and Snowling, 2001; Wagensveld et al., 2012). In contrast, first grade children seem to be less sensitive to this so-called global similarity effect (CardosoMartins, 1994), which is possibly a result of their reading 
experience which is known to lead to more developed phonological awareness (Adams, 1990; Blachmann, 2000; Snowling and Hulme, 2005). Although there are event-related potential (ERP) studies that have examined rhyme processing in young children, the global similarity effect has not been studied in young children by means of this method. We will therefore investigate the neural correlates that play a role in rhyme processing and the processing of other types of phonological overlap in preliterate kindergartners and reading second grade children.

\subsection{Rhyme processing in the brain}

Neural correlates of rhyme have first been studied in adults. ERP research has shown that the human brain responds differently to rhyming and non-rhyming words. This effect was first described by Rugg $(1984 a, b)$ who found that, in a visual rhyme judgment task, non-rhyming words elicited a more negative deflection in the ERP waveform than rhyming words. For example, the target word cause, which was preceded by the non-rhyming prime word clams, led to a more negative deflection than the similar target word pause, which was preceded by the rhyming prime word claws. In addition to these results with words, the effect was also observed when pseudoword stimuli were used. The rhyme effect was maximal around $450 \mathrm{~ms}$ after the onset of the target and was found mainly around the midline and over the right hemisphere. The observed component that was involved in the effect was originally described as a separate rhyme-sensitive ERP component and named N450 component after its peak-latency. The N450 component has also been described as a more general sensitivity to phonological mismatch of the N400 component (Perrin and GarciaLarrea, 2003, Praamstra et al., 1994, Radeau et al., 1998); the ERP component that is involved in semantic processing (Kutas and Hillyard, 1980, 1984). Therefore, the component has also been labeled the phonological N400. However, in the present study, we will refer to the component using the original N450 terminology to prevent misunderstandings.

Since the initial publications by Rugg, various studies have examined the properties of the N450 component and the N450 rhyme effect. From these studies, it has become clear that the N450 rhyme effect can be elicited by a wide range of stimuli varying from relatively simple items, such as single letters (Coch et al., 2008b), to more complex multi-syllabic pseudowords (Dumay et al., 2001). Praamstra and Stegeman (1993) found that the component is not solely elicited by visual stimuli. In a phonological priming study, they showed that auditory stimuli also influenced the N450 amplitude, even when the prime and target (pseudo)words were spoken by a different speaker. Furthermore, a study exploring the role of visual features showed that the N450 component did not differ for letters that were presented in lowercase or uppercase (Coch et al., 2008a). In conclusion, the N450 component can be considered as a merely phonological measure, since the component was not influenced by physical orthographic features.

Measuring EEG has several advantages. First, the method provides insight into the neural processes that take place immediately after presentation of the stimulus and can therefore display processing differences that precede any physical responses that are measured in behavioral research. Another advantage is that the method is non-invasive, unlike other neuro-imaging techniques (e.g., functional magnetic resonance imaging), which makes it a very suitable method to use when examining children. A series of children studies performed by Coch and colleagues have addressed the developmental pattern of the N450 rhyme effect. In a rhyming study using visual stimuli they examined children (who could already read) and adults in age groups ranging from 7 to 23 years old (Grossi et al., 2001). They found that the N450 rhyme effect is already present at age 7 and does not change during further development; the distribution and amplitude of the effect were stable across the age groups. The same results were obtained in a study using auditory stimuli (Coch et al., 2002) and more recent in a letter-rhyme task (Coch et al., 2011). Although the distribution and amplitude of the N450 rhyme effect are rather stable, the onset is more variable. In a more recent ERP study Coch et al. (2005) investigated rhyme effects in 6-, 7- and 8-year-old reading children with low and high phonological awareness skills. Although no amplitude differences were found, the onset of the N450 rhyme effect appeared to be later for the children with low phonological awareness scores. Also, studies examining participants with reading difficulties have found that poor readers showed decreased N450 rhyme effects as compared to typical readers (Ackerman et al., 1994; Desroches et al., 2012; McPherson et al., 1998), indicating that the N450 rhyme effect is influenced by different levels of reading.

Although the N450 component was first observed using rhyming stimuli, the effect does not seem to be restricted to rhyme overlap at the end of a word. Modulations of the N450 have also been found when non-rhyming stimuli were contrasted with alliterating stimuli (e.g., beeld-beest) in adults (Praamstra et al., 1994), in typically developing preliterate and literate and even dyslexic children (Bonte and Blomert, 2004a,b). Furthermore, the N450 rhyme effect can also be elicited by word-final overlap that is larger or smaller than the rime constituent of a word. Dumay et al. (2001) examined phonological priming using bi-syllabic French words and pseudowords. In this study the targets were preceded by primes that overlapped in syllable (e.g., lurage - tirage), rime (e.g., lubage-tirage) or coda (e.g., lusoge - tirage). The responses to these experimental conditions were compared to responses to a control condition which consisted of unrelated prime-target pairs (e.g., lusole-tirage). The ERP results showed that all three experimental conditions led to a reduction of the $\mathrm{N} 450$ amplitude. Interestingly, the amount of phonological overlap had a graded effect on the amplitude of the N450. The amplitude reduction was largest for syllable overlap, intermediate for rime overlap and smallest for coda overlap as compared to the unrelated control condition. Thus, the N450 appears to be sensitive to the degree of phonological overlap, which makes it a suitable instrument to explore differences in ERP between rhyme and other types of phonological overlap.

\subsection{Rhyme processing in children: the global similarity effect}

Behavioral research has shown that kindergarten children who can make rhyme judgments on simple word pairs such as wall-ball are easily confused when they are presented with words that contain another type of phonological overlap such as bell-ball. These phonological distracters are often judged incorrectly as rhyming pairs (Cardoso-Martins, 1994; Carroll and Snowling, 2001). This so-called global similarity effect has been explained as a result of the ill-defined phonological representations in a young child's mental lexicon (Carroll and Snowling, 2001; De Cara and Goswami, 2003; Walley et al., 2003). In a recent behavioral study we attempted to shed light on the role of lexical representations in rhyme processing (Wagensveld et al., 2012). Dutch children were presented with a rhyme judgment task containing rhyming pairs (e.g., gek-bek, "strange-beak"), overlapping pairs that shared the same onset and coda consonant (e.g., bak-bek, "box-beak") and unrelated pairs (e.g., sop-bek, "lather-beak"). To examine the role of lexical representations in the judgment of these word pairs the children were also presented with a series of Dutch pseudo-

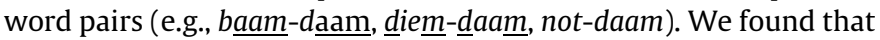
preliterate children were slower and made more errors for the pseudowords which indicated that they could not solely rely on the mental lexicon for their pseudoword judgments. Interestingly, we observed an equally large global similarity effect in word and 
pseudowords: overlapping items were judged more slowly and less accurately than unrelated non-rhyming items. This observation indicated that the effect cannot solely be explained by poorly specified lexical representations. Instead, we proposed that the brain automatically registers similarities in perceived stimuli, a process which is followed by a more analytical judgment of rhyme overlap.

\subsection{The present study}

In the present study we focused on the neural correlates that are involved in rhyme processing in young children before and after they have learned how to read. Our aim was to see how the global similarity effect that has been shown in behavioral studies is reflected in the neural pattern of the developing brain. To the best of our knowledge, the present study will be the first to examine if an N450 effect can be found in a rhyming experiment with preliterate children from the age of five and the first study to examine the neural correlates of the global similarity effect in children. The study addressed two main research questions. Our first question was if an N450 rhyme effect could be observed in preliterate and literate children to a similar extend? Our second main question was whether the N450 component in young children is solely sensitive to rhyme could or if it could be modulated by different types of phonological overlap in particular items that are globally similar but do not rhyme?

\section{Methods}

\subsection{Participants}

Participants were 43 native monolingual Dutch speaking children of which 22 were in kindergarten in the year prior to formal reading education ( 10 girls; average age 5 years and 7 months, SD 4 months); and 21 were in second grade (14 girls; average age 7 years and 6 months, SD 6 months). One second grade child was excluded from the analysis due to inadequate performance (less than 34\% correct and response times of more than 2600 ms occurring regularly in all three conditions). In a questionnaire, the parents of the children indicated them to be right-handed. All children had normal hearing and (corrected to) normal sight and none had a known history of neurological problems. The study was approved by the national ethics committee and the parents of all participants signed an informed consent form.

\subsection{Linguistic development assessment}

Prior to the ERP measures the two groups of children were presented with four standardized screening measures to assess their basic linguistic abilities (Verhoeven, 2011). The first task was a letter knowledge task examining the amount of graphemes a child knows. The child was presented with a chart containing 34 graphemes that corresponded to the 33 Dutch phonemes, and was asked to name these out loud. Both the letter name as the letter sound, were considered as correct identifications of the kindergarten children. Responses were scored as either correct or incorrect. Secondly, a rapid picture naming task was administered to assess the child's ability to quickly retrieve concepts. During this task, the child was presented with a chart containing repetitive images of five common objects. The child was asked to name the pictures as quickly as possible. The score was based on the amount of images a child named correctly in one minute.

Furthermore, two measures of auditory short term memory were taken: a word span task and a pseudoword repetition task. During the word span task, the experimenter spoke sequences of
Table 1

Mean frequency and duration of stimuli used in the rhyme judgment task. Mean frequencies are presented in percentages which are taken from the 'Streeflijst woordenschat voor zesjarigen', an index of vocabulary knowledge of Dutch speaking six-year-old children. Mean durations are presented in milliseconds. Standard deviations of the mean are in parentheses.

\begin{tabular}{lll}
\hline & Mean frequency & Mean duration \\
\hline Rhyming primes & $94(4)$ & $538(89)$ \\
Overlapping primes & $94(4)$ & $529(99)$ \\
Unrelated primes & $92(6)$ & $533(88)$ \\
Targets & $93(5)$ & $522(87)$ \\
Filler primes & $94(5)$ & $545(84)$ \\
Filler targets & $95(4)$ & $549(68)$ \\
\hline
\end{tabular}

monosyllabic Dutch words out loud, which the children were asked to repeat. There were twelve sequences provided, which varied in length from two to seven words. Responses were scored as either correct or incorrect and the test was ended if a child was unable to repeat four consecutive sequences. In the pseudoword repetition task, the children were asked to repeat pseudowords, which were spoken out loud by the experimenter. In total, 40 pseudowords were presented varying in length from one to six syllables. Responses were scored as either correct or incorrect. The task was ended if a child failed to repeat five consecutive pseudowords. The letter knowledge task was only offered to the preschool children, the other three tasks were presented to both groups. Any relations between the observed ERP effects and the four linguistic ability tests were examined by performing Pearson's correlations. Only significant correlations will be reported.

\subsection{Stimuli}

Stimuli consisted of 36 Dutch monosyllabic target words with a CVC structure ${ }^{2}$ (e.g., pijn). Each of the targets was combined with three types of prime words; rhyming (e.g., wijn) unrelated (e.g., boom) and overlapping primes (e.g., pen). This resulted in 36 rhyming and 72 non-rhyming pairs. To prevent children from having a possible response bias indicating pairs as non-rhyming, 36 monosyllabic rhyming filler pairs were created. This led to an even rhyme vs. non-rhyme probability of $50 \%$. Examples of the stimuli can be found in Appendix A: Table A1.

All words were selected from the 'Streeflijst Woordenschat voor Zesjarigen' (Schaerlaekens et al., 1999), an index of vocabulary knowledge of 6-year-old Dutch speaking children. The list gives an overview of all Dutch words with the percentage of Dutch and Belgian teachers who expect 6-year-old children to understand the word. All selected words were indexed above $80 \%$. The average percentages of the words can be found in Table 1 .

Stimuli were digitally recorded $(44.1 \mathrm{kHz}$, stereo) on a Dell D610 latitude laptop running the Sony Sound Forge recording program. The stimuli were spoken into a Sennheiser ME62 m icrophone by a female speaker in a sound attenuated room. After recording, each stimulus was carefully edited for precise onset and offset using a speech waveform editor (Praat, version 4.5.12). Mean durations of the targets and the rhyming, overlapping and unrelated primes can be found in Table 1.

\subsection{Procedure}

EEG measurements took place in a mobile lab built into a Volkswagen minivan which was placed near the school of the children.

\footnotetext{
2 Diphtong vowels, consisting of two adjacent vowels that occur within the same syllable, are common in Dutch. Therefore the 'ij' from the examples pijn and wijn and the 'oo' from boom can be considered as one vowel, hence these words have a CVC structure rather than CVCC or CVVC.
} 
During the EEG experiment the child listened to word pairs that were played over headphones at $65 \mathrm{~dB}$ and was instructed to indicate as fast with a button press as possible whether the two words of a word pair rhymed or not. Response hands and buttons were counterbalanced over subjects. Before the experiment started, the experimenter held a short rhyme practice session with the child. The experimenter provided a word and encouraged the child to think of a rhyming word. Incorrect answers were corrected and then the child was provided with a new word. After the child had provided three consecutive correct rhyme words, the child was presented with a practice version of the experiment on the computer. During this practice phase, the child learned which response (rhyme or non-rhyme) corresponded to which button (left or right).

During the experiment each target was presented three times, each time with a prime from a different condition (i.e. rhyme, overlap, unrelated). Each trial began with a fixation cross in the middle of the screen for $950 \mathrm{~ms} ; 1000 \mathrm{~ms}$ after trial onset the prime word was presented; $1200 \mathrm{~ms}$ after the prime the target word was presented. The total duration of one trial was $6000 \mathrm{~ms}$. The experiment was divided in three blocks with a short pause in between. In each block a target was only presented once with one of its three primes (rhyming, unrelated or overlapping). The order of blocks was counterbalanced over participants.

\subsection{EEG recordings}

EEG was recorded from 28 active electrodes using the Acticap system with $\mathrm{Ag} / \mathrm{AgCL}$ electrodes (Brain Products, Gilching, Germany). Electrodes were mounted in an elastic cap, each referred to the left mastoid. Electrodes were located at four midline sites (Fz, FCz, Cz and $\mathrm{Pz}$ ) and 24 lateral sites (Fp1/Fp2, F7/8, F3/4, FC5/6, FC1/2, C3/4, CP5/6, CP1/2, P7/8, P3/4, T7/8, 01/2). Recordings from $\mathrm{Fp} 1$ and an electrode placed beneath the left eye were used to monitor vertical eye movement whereas horizontal eye movement was monitored via a bipolar montage with electrodes at the outer canthi of the left and right eye. Recordings were re-referenced off-line to average mastoids. Signals were pre-amplified at the scalp and all impedances were kept below $20 \mathrm{k} \Omega$ for all channels, which is a standard setting for active electrodes. Recordings were amplified using a BrainAmp DC amplifier system (Brainproducts) and digitized online at a sampling rate of $500 \mathrm{~Hz}$ using a bandpass filter of $1-30 \mathrm{~Hz}$. The EEG and EOG were recorded and digitized using Brain Vision Recorder software (1.03, Brain Products, Gilching, Germany).

\subsection{Behavioral data analyses}

The behavioral data were examined by performing one ANOVA per participant group with phonological condition (rhyme, overlap, unrelated) as a within subject factor. Significant main effects were further investigated by conducting $t$-tests on the following planned comparisons; rhyme vs. overlap, overlap vs. unrelated, rhyme vs. unrelated.

\subsection{EEG data analyses}

EEG data were analyzed off-line using the Brain Vision Analyzer Software package. The data were rereferenced to average mastoids, corrected for ocular motion ${ }^{3}$ (Gratton et al., 1983) and digitally filtered between 1 and $30 \mathrm{~Hz}$. Data were averaged over an epoch of $1200 \mathrm{~ms}$. On these segments a baseline correction of -150 to 0

\footnotetext{
${ }^{3}$ Since the children were too young for an eye blink instruction we decided to remove eye artifacts offline using the Gratton-Coles method (Gratton et al., 1983).
}

was carried out, after which all segments with amplitudes below $-100 \mu \mathrm{V}$ and above $100 \mu \mathrm{V}$ were automatically rejected (kindergarten mean $=6.6 \%, \mathrm{SD}=7.5 \%$, second grade mean $=4.4 \%, \mathrm{SD}=6.0 \%$ ). For kindergartners this resulted in 29 (SD 5), 25 (SD 9) and 30 (SD 5 ) remaining trials on average for the rhyming, overlapping and unrelated condition, respectively. For second graders there were on average 33 (SD 2), 31 (SD 3) and 32 (SD 3) trials left in the rhyming, overlapping and unrelated condition, respectively. Segments were averaged per participants, per condition and per electrode site.

ERP effects were examined by means of an overall repeated measures analyses of variance (ANOVAs) which were performed on the mean amplitude of a time window. Since visual inspection of the data showed that both groups displayed very distinct patterns data were analyzed for each group separately (for a similar approach, see Bonte and Blomert, 2004a). Time-windows of interest were based on visual inspection and had three within-subject factors: Condition (Rhyme, Overlap, Unrelated), Hemisphere (Left, Right) and Anteriority (Anterior and Posterior). Electrodes were assigned to cluster in the following way: left anterior ((F7, F3, FC5, FC1, VB), right anterior ((F8, F4, FC6, FC2, Fp2), left posterior (C3, $\mathrm{CP} 1, \mathrm{CP} 5, \mathrm{P} 7, \mathrm{P} 3, \mathrm{O} 1)$ and right posterior (C4, CP2, CP6, P8, P4, O2). Greenhouse-Geisser correction for violation of sphericity assumption was applied when appropriate (Greenhouse and Geisser, 1959). ANOVAs were performed for each group (kindergarten and second grade) separately since visual inspection showed that the two groups had two distinct response patterns.

\section{Results}

\subsection{Behavioral outcomes}

\subsubsection{Outcomes of the linguistic development assessment}

An independent samples $t$-test was conducted to compare the performance of the kindergarten and second grade children on three linguistic screening measures. The outcomes are represented in Table 2 together with the mean scores per group.

The data show that second grade children perform significantly better at rapid picture naming, word span and pseudoword repetition. Letter knowledge was only examined in the kindergarten children; on average they were able to identify 10.1 (SD 8.8) graphemes (range 2-31).

\subsubsection{Behavioral outcomes of the rhyme task}

Fig. 1 displays the mean response times (panel $A$ ) and error scores (panel B) of the rhyme task. As is apparent from this figure, kindergartners found the rhyme judgment task more difficult; they made more errors and had slower response times than the second grade children. The mean accuracy score was $87 \%$ (SD 20) for the kindergarten children and 92\% (SD 16) for the second graders, indicating that both groups were able to carry out the task. However, both kindergartners and second graders seem to have more difficulty judging overlapping word pairs (i.e., responding "no" to a pair such as pen-pijn) than unrelated word pairs (such as boom-pijn).

Since the ERP data of both groups were analyzed independently due to the distinct patterns of both groups, behavioral outcomes were also processed separately, in order to be consistent. A comparison between the two non-rhyming conditions ${ }^{4}$ showed that especially second grade children judged overlapping items less accurate than unrelated items $(t(20)=2.85, p<.01, d=0.90)$, a pattern which was marginally significant for kindergartners $(t(21)=1.93$, $p<.07, d=0.60$ ). Kindergartners responded slower to overlapping

\footnotetext{
${ }^{4}$ The overlapping condition requires a different response than the rhyming condition. It can therefore better be weight against the unrelated condition, which should also be judged as not rhyming. This way, the observed effects cannot be the result of a response bias of just saying 'yes' to each item.
} 
Table 2

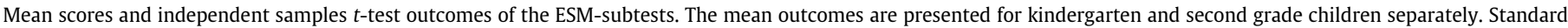
deviations of the mean are presented in parentheses.

\begin{tabular}{|c|c|c|c|c|c|}
\hline & \multirow{2}{*}{$\begin{array}{l}\text { Kindergarten } \\
\text { Mean (SD) }\end{array}$} & \multirow{2}{*}{$\begin{array}{l}\text { Second grade } \\
\text { Mean (SD) }\end{array}$} & \multicolumn{3}{|c|}{ Independent samples $t$-test } \\
\hline & & & $t$ & $\mathrm{~d} f$ & $p$ \\
\hline Rapid picture naming & $40.0(6.9)$ & $55.4(9.7)$ & -6.07 & 42 & 0.001 \\
\hline Word span & $4.9(1.7)$ & $6.6(1.5)$ & -3.56 & 42 & 0.001 \\
\hline Pseudoword repetition & $31.2(5.4)$ & $36.3(3.7)$ & -3.67 & 42 & 0.000 \\
\hline
\end{tabular}

A. Response time

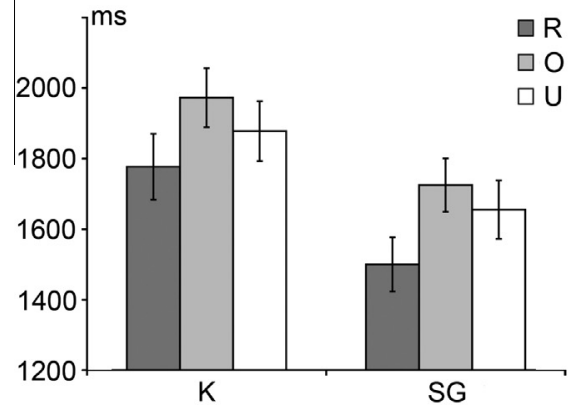

B. Errors

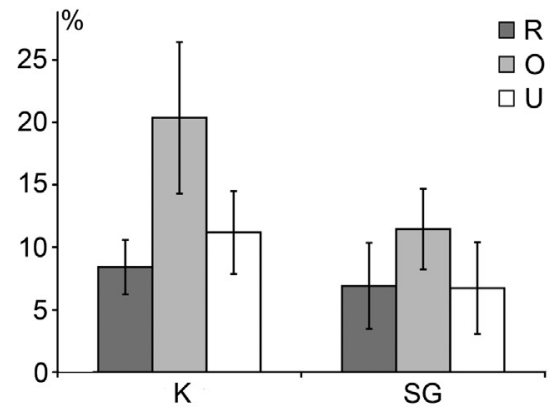

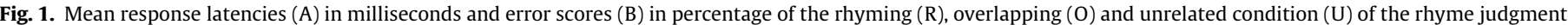
task. The outcomes are presented for kindergarten (K) and second grade children separately (SG). The bars represent the standard error of the mean.

than unrelated items $(t(21)=3.03, p<.01, d=0.94)$. For second graders the difference in response time to overlapping and unrelated items failed to reach significance $(t(20)=1.81, p<0.9, d=0.57$ ). Thus, the global similarity effect was present in the accuracy data of both groups, as well as in the response latency outcomes of the kindergartners.

\subsection{Electrophysiological outcomes}

Fig. 2 displays the grand average waveforms for the rhyming, overlapping and unrelated condition for both second graders (panel A) and kindergarten children (panel B). The grand averages were time-locked to the onset of the target. Table 3 represents the mean amplitudes and their standard deviations in microvolt per condition and scalp region for each of the examined time-windows for second graders (Panel A) and kindergartners (Panel B).

\subsubsection{Second graders}

Our first question was whether we could observe an N450 effect in young children. Visual inspection of the data showed that second graders displayed an N450 effect for the rhyming compared to the non-rhyming conditions between 200 and $450 \mathrm{~ms}$. For this window a 3 (condition; rhyme, overlap, unrelated) $\times 2$ (hemisphere; left, right) $\times 2$ (anteriority; anterior, posterior) overall ANOVA was performed. Electrodes were assigned to a cluster as follows: left anterior ((F7, F3, FC5, FC1, VB), right anterior ((F8, F4, FC6, FC2, Fp2), left posterior (C3, CP1, CP5, P7, P3, O1) and right posterior (C4, CP2, CP6, P8, $\mathrm{P} 4, \mathrm{O} 2)$. The ANOVA showed that there was an interaction between anteriority and condition $\left(F(2,40)=6.30, p<.005, \eta_{p}^{2}=2.12\right)$. To examine this interaction two ANOVAs were performed; a 3 (condition; rhyme, overlap, unrelated) $\times 12$ (electrode: VB, Fp2, F7, F3, $\mathrm{Fz}, \mathrm{F} 4, \mathrm{~F} 8, \mathrm{FC} 5, \mathrm{FC} 1, \mathrm{FC}, \mathrm{FC} 2, \mathrm{FC} 6)$ including anterior electrodes and a 3 (condition; rhyme, overlap, unrelated) $\times 12$ (electrode: $\mathrm{C} 3$, $\mathrm{Cz}, \mathrm{C} 4, \mathrm{CP} 5, \mathrm{CP} 1, \mathrm{CP} 2, \mathrm{CP} 6, \mathrm{P} 7, \mathrm{P} 3, \mathrm{Pz}, \mathrm{P} 4, \mathrm{P} 8, \mathrm{O} 1, \mathrm{O} 2$ ) including posterior electrodes. Outcomes showed that the effect of condition was centered at posterior locations $\left(F(2,40)=5.24, p<.01, \eta_{p}^{2}=28.66\right)$. There was no main effect of condition found at anterior locations. The significant main effect of condition found in the ANOVA of posterior electrodes was further examined by means of paired sample $t$-tests and showed that at posterior sites, rhyming targets elicited a smaller $\mathrm{N} 450$ than unrelated $(t(20)=2.43, p<.05$, $d=.67)$ and overlapping targets $(t(20)=3.27, p<.005, d=1.00)$.

The second question concerned sensitivity of the N450 component to types of overlap other than rhyme. A comparison of the non-rhyming conditions at posterior sites showed that there was no significant difference between these conditions $(t(20)=-1.29$, $p=.21, d=.30$ ). The waveform of the overlap condition resembled the waveform of the unrelated condition, despite the phonological overlap between prime and target. Thus, in second grade children the N450 is modulated by rhyme overlap but not by consonant overlap in word pairs.

Visual inspection of the data of second graders further led to the investigation of a second time window. From 550 to $750 \mathrm{~ms}$ the ERPs showed a positive deflection for all three conditions. However, at posterior electrode sites this late positive deflection seems to be reduced for the rhyming target pairs in comparison to the other two conditions. An overall ANOVA was undertaken and showed a difference in the distribution of the effect $(F(2,40)=3.68, p<.05$, $\left.\eta_{p}^{2}=2.84\right)$. ANOVAs of anterior and posterior electrodes provided some indication that the effect in second graders was more prominent on posterior sites $\left(F(2,40)=1.31, p=.08, \eta_{p}^{2}=1.42\right)$ than anterior sites $\left.F(2,40)=.07, p=.94, \eta_{p}^{2}=39.42\right)$. However, since the main effect observed at posterior sites did not reach significance, no further analyses steps were undertaken.

\subsubsection{Kindergartners}

Visual inspection of the kindergarten data led to the examination of three other time windows of interest. The first effect (i.e., 100-200 ms time window) was not observed in second graders so this was specific for the kindergarten group. The second window (i.e., 250-400 ms) was in proximity to the N450 effect window that was observed in second graders. The third time frame of interest resembled the later effect that was also observed in second graders (i.e., $550-750 \mathrm{~ms}$ ). For all three windows an overall ANOVA was performed, followed by ANOVAs of anterior and posterior electrodes when interactions were observed. Significant effects were further explored by performing paired sample $t$-tests.

The first effect, which was not observed in the second graders, showed an early negativity from 100 to 200 ms after stimulus on- 


\section{A. Second Grade}
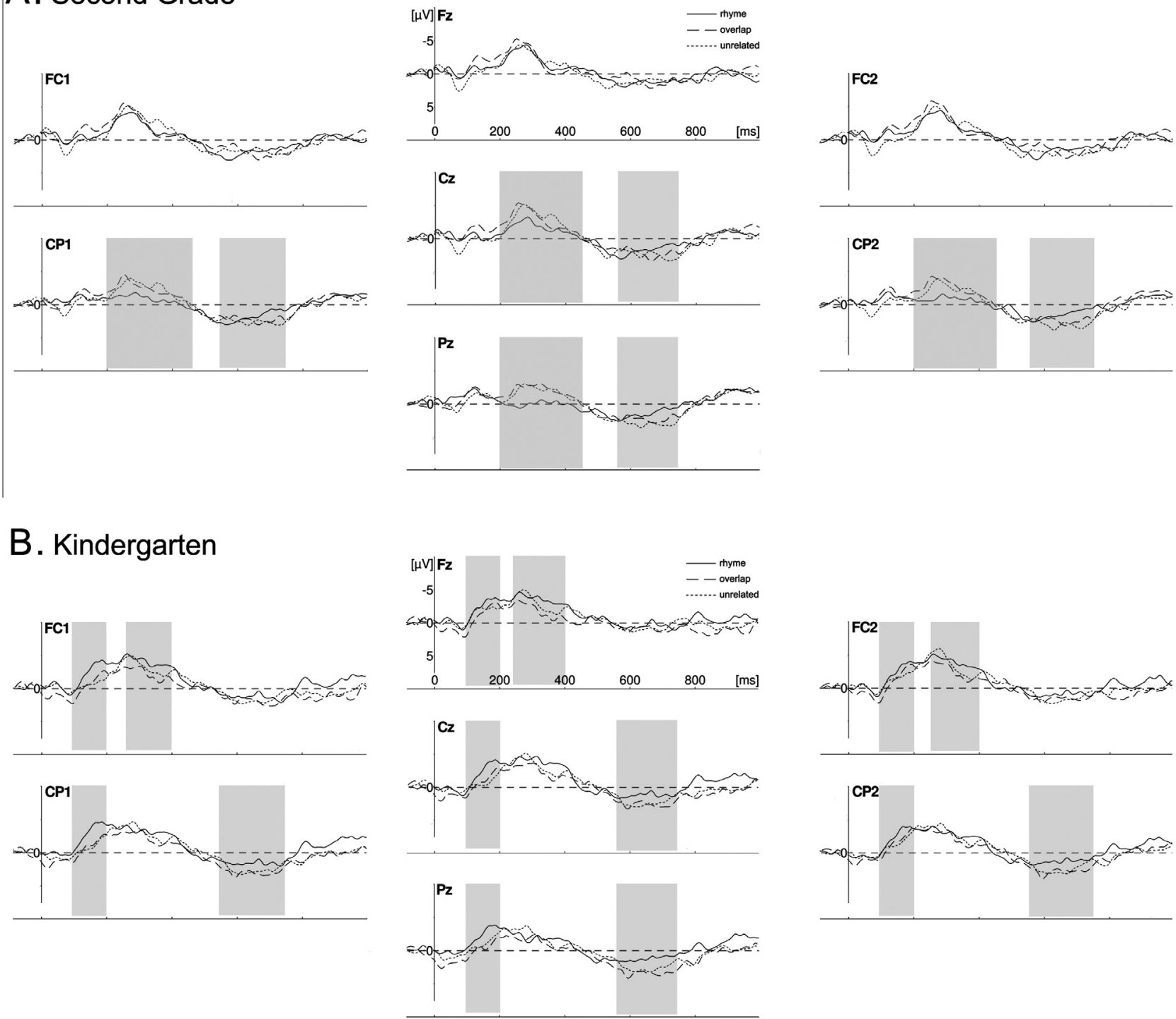

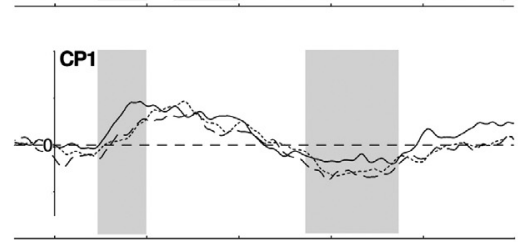

\section{B. Kindergarten}

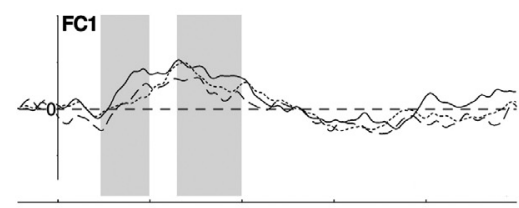

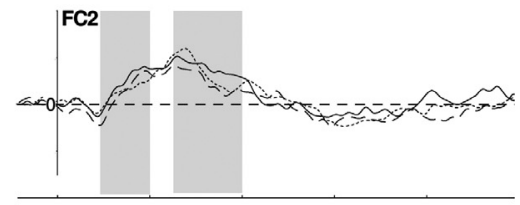

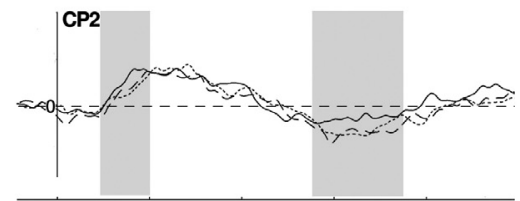

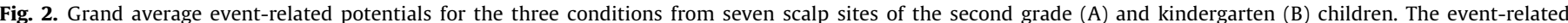

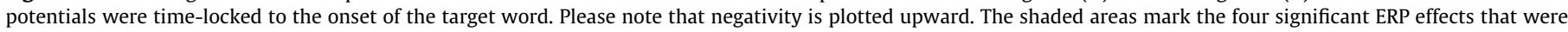

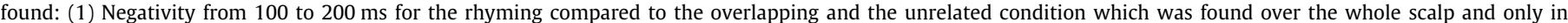

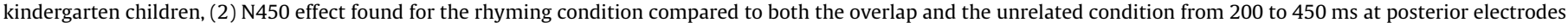

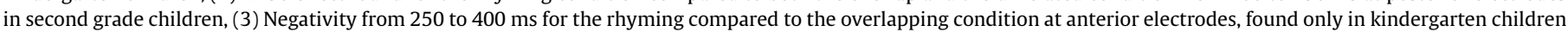

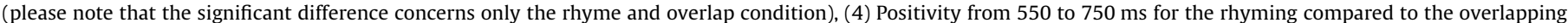
and the unrelated condition which was found at posterior electrodes in both kindergarten and second grade children.

set for rhyming compared to non-rhyming targets (Fig. 3, electrode $\mathrm{Cz}$ ). The overall ANOVA showed that the ERP effect was found over the whole scalp and although the main effect of condition was marginally significant $\left(F(2,42)=3.03, p=.06, \eta_{p}^{2}=9.62\right) t$-tests were performed in order to examine this effect more thoroughly. Paired sample $t$-test revealed the rhyme condition differed significantly from both the overlap condition and the unrelated condition $\left(t_{\mathrm{RO}}(21)=-2.15, p<.05, d=.54 ; t_{\mathrm{RU}}(21)=-2.23, p<.05, d=.51\right)$.

The time frame of the second effect in kindergartners, i.e., 250$400 \mathrm{~ms}$, was in close proximity to the N450 rhyme effect that was observed in second graders. An overall ANOVA showed an interaction between anteriority and condition $(F(2,42)=4.22, p<.05$, $\eta_{p}^{2}=2.72$ ). Follow-up ANOVAs revealed that effect was located at the anterior electrodes $\left(F_{\text {ant }}(2,42)=-2.28, p<.05, \quad \eta_{p}^{2}=47.4\right)$. Paired sample $t$-test showed that the observed effect was a result of a difference between the rhyming and overlapping condition only $(t(2,21)=-2.28, p<.05, d=.52)$. The effect was observed in approximately the same time window as the previously described N450 in second graders. The anterior electrodes displayed in Fig. 2 show that the effect was reversed in comparison to the rhyme effect in second graders; rhyming targets elicited a larger N400 than overlapping targets. A bivariate correlation analysis of this effect and the amount of letter knowledge $(r=-.55, p<.01)$ indicated that the less letter knowledge children have, the larger this frontal negativity is (see also Fig. 3).

The third effect was observed in a later time window and resembled the findings in second grade children. In kindergartners, the ERPs also showed a positive deflection for all three conditions from 550 to $750 \mathrm{~ms}$, which seems to be reduced at posterior sites for the rhyming target pairs in comparison to the other two conditions. An overall ANOVA showed an interaction between anteriority and condition in kindergartners $\left(F(2,42)=3.89, p<.05, \eta_{p}^{2}=2.18\right)$. Separate ANOVAs for anterior and posterior sites showed that he effect was found to be significant only at posterior electrode sites 
Table 3

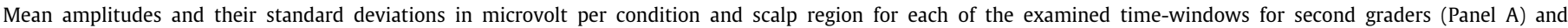
kindergartners (Panel B).

\begin{tabular}{|c|c|c|c|c|c|c|c|c|c|}
\hline \multicolumn{10}{|c|}{ A. Second graders } \\
\hline \multirow[t]{2}{*}{ Scalp region } & & \multicolumn{4}{|l|}{$200-450 \mathrm{~ms}$} & \multicolumn{4}{|c|}{$550-750 \mathrm{~ms}$} \\
\hline & & Rhyme & Overlap & \multicolumn{2}{|c|}{ Unrelated } & Rhyme & \multicolumn{2}{|c|}{ Overlap } & Unrelated \\
\hline \multicolumn{10}{|l|}{ Anterior } \\
\hline \multicolumn{10}{|l|}{ Left } \\
\hline$M$ & \multirow{2}{*}{\multicolumn{2}{|c|}{$\begin{array}{r}-1.95 \\
187\end{array}$}} & -1.91 & \multicolumn{2}{|c|}{-2.10} & 1.04 & \multicolumn{2}{|c|}{0.67} & 0.76 \\
\hline SD & & & 1.94 & \multicolumn{2}{|c|}{1.87} & 2.53 & \multicolumn{2}{|c|}{1.86} & 1.77 \\
\hline \multicolumn{10}{|l|}{ Right } \\
\hline$M$ & \multicolumn{2}{|r|}{-2.43} & -2.24 & \multicolumn{2}{|c|}{-2.49} & 0.72 & \multicolumn{2}{|c|}{0.70} & 0.70 \\
\hline SD & \multicolumn{2}{|r|}{2.05} & 2.25 & \multicolumn{2}{|c|}{1.75} & 2.50 & \multicolumn{2}{|c|}{1.61} & 1.98 \\
\hline \multicolumn{10}{|l|}{ Posterior } \\
\hline \multicolumn{10}{|l|}{ Left } \\
\hline$M$ & \multirow{2}{*}{\multicolumn{2}{|c|}{$\begin{array}{r}-0.37 \\
1.54\end{array}$}} & -1.46 & \multicolumn{2}{|c|}{-1.40} & 1.40 & \multicolumn{2}{|c|}{1.99} & 2.12 \\
\hline SD & & & 1.75 & & & 1.90 & & & 1.81 \\
\hline \multicolumn{10}{|l|}{ Right } \\
\hline$M$ & & -0.13 & -1.63 & & & 1.13 & & & 2.71 \\
\hline SD & & 1.64 & 1.75 & & & 1.68 & & & 1.60 \\
\hline B. Kindergart & & & & & & & & & \\
\hline Scalp region & $100-20 c$ & $0 \mathrm{~ms}$ & & $250-40$ & & & $550-75$ & & \\
\hline & Rhyme & Overlap & Unrelated & Rhyme & Overlap & Unrelated & Rhyme & Overlap & Unrelated \\
\hline Anterior & & & & & & & & & \\
\hline Left & & & & & & & & & \\
\hline$M$ & -2.65 & -1.29 & -1.61 & -3.64 & -1.97 & -2.62 & 0.67 & 0.46 & 0.15 \\
\hline SD & 1.90 & 2.02 & 2.91 & 3.25 & 2.18 & 2.64 & 2.01 & 2.02 & 1.53 \\
\hline Right & & & & & & & & & \\
\hline$M$ & -3.01 & -2.06 & -2.37 & -3.67 & -2.28 & -3.05 & 0.10 & 0.20 & -0.07 \\
\hline SD & 1.96 & 2.41 & 3.22 & 3.59 & 2.26 & 3.10 & 1.97 & 2.17 & 1.77 \\
\hline Posterior & & & & & & & & & \\
\hline Left & & & & & & & & & \\
\hline$M$ & -2.05 & -0.62 & -0.60 & -1.67 & -1.42 & -1.35 & 1.86 & 2.75 & 2.40 \\
\hline SD & 2.55 & 2.98 & 2.20 & 2.49 & 2.37 & 2.05 & 1.96 & 2.13 & 2.25 \\
\hline Right & & & & & & & & & \\
\hline$M$ & -1.77 & -1.48 & -0.97 & -1.40 & -1.39 & -1.47 & 1.50 & 2.45 & 2.49 \\
\hline SD & 2.51 & 2.30 & 2.58 & 2.63 & 2.16 & 2.01 & 1.91 & 1.61 & 2.53 \\
\hline
\end{tabular}

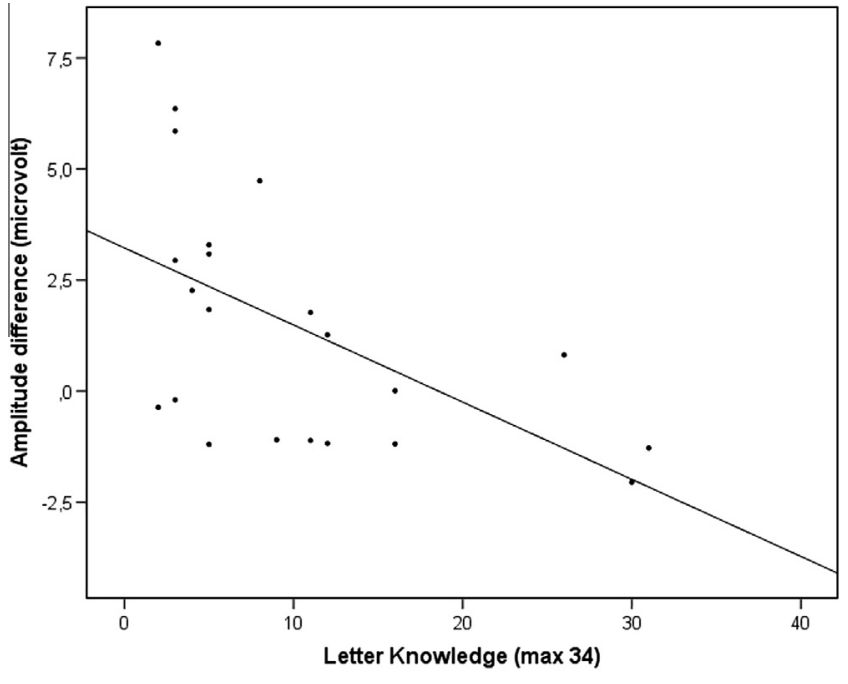

Fig. 3. Scatter plot representing the relationship in kindergartners between the amount of letter knowledge and the mean amplitude difference between the overlap and rhyme condition averaged across the ten anterior electrodes from 250 to $400 \mathrm{~ms}$.

$\left(F(2,42)=3.31, p<.05, \eta_{p}^{2}=27.95\right)$. Paired sample $t$-test showed that this effect was the result of an amplitude difference between the ERPs of the rhyming and unrelated condition $(t(21)=-3.13$, $p<.005, d=.63$ ).

\section{Discussion}

The present study examined the behavioral and neural responses of kindergarten and second grade children to word pairs that either shared a rhyme overlap, an overlap in onset and final consonant or were phonologically unrelated. Our aim was to find out how the global similarity effect that has been shown in behavioral studies (e.g., Cardoso-Martins, 1994; Carroll and Snowling, 2001; Wagensveld et al., 2012) is reflected in the neural patterns of children with and without reading experience.

\subsection{The N450 rhyme effect in second graders}

The second grade children showed a distinct rhyme effect. Between 200 and $450 \mathrm{~ms}$ after the onset of the target the rhyming condition elicited a smaller N450 than the unrelated condition. Concurrent with this, the behavioral data showed that the rhyming items were judged faster than the unrelated items by the second graders. The neural outcomes are consistent with the findings of the small number of studies that examined neural responses to rhyme judgment in children (Coch et al., 2002; Grossi et al., 2001).

New however, is the finding that word pairs that did not rhyme, but shared a different type of phonological overlap (e.g., pen-pijn, "pen-pain") elicited an N450 that resembles the N450 of the unrelated items. This contradicted the findings of a study examining adults that showed a graded response pattern of the N450 amplitude difference which was largest for syllable overlap, intermediate for rhyme and smallest for phoneme overlap (Dumay et al., 
2001). In the present study we could not obtain any evidence for a graded response pattern of the N450 component. Second grade children only show a graded response in the form of a global similarity effect in the behavioral data suggesting that, contrary to the N450 in adults, the N450 in second grade children primarily reflects rhyme processing and is not modulated by other types of phonological overlap. The discrepancy between behavioral data and EEG data will be addressed in more detail in the final part of the discussion (see 3.4 implications).

A possible explanation for this observation lies in the differential state of the lexical representations of young and experienced readers. We expected that second grade children with reading experience would show an adult-like pattern since reading experience is known to result in better phonological and phonemic awareness (Blachmann, 2000). The absence of this adult-like graded response to different types of overlap could indicate that the two years of reading experience have not yet led to the completely specified phonological representations that adults have. The second graders seem to be able to quickly and automatically decode the words into an onset and a rime constituent and they can make correct decision on word pairs that share intra-syllabic overlap. However, the length of the response times to the overlap condition indicates that the processing of these items is more difficult; they cannot yet automatically detect small intra-syllabic changes in a way that adults can due to their years of reading experience.

Furthermore, it is also possible that the lack of graded response in the ERP wave form of the overlapping items could be due to a difference in task instruction. In the study by Dumay and colleagues (2001) the participants judged the pairs on their lexical status. They were not instructed to monitor the items for a certain type of phonological overlap such as rhyme. The children in the present study were specifically instructed to respond only to rhyme overlap. It is therefore possible that, as a result of this specific instruction, the neural patterns will also only respond to rhyme and not to other types of phonological overlap. The idea that the N450 effect depends on instruction is further supported by the finding that it can only be obtained in when participants are actively engaged in the experiment; the N450 effect could not be observed in the absence of a task (Perrin and Garcia-Larrea, 2003).

\subsection{Neural rhyme effects in kindergartners}

Although we could not observe a typical N450 rhyme effect in the kindergarten group there were some other effects observed both on a behavioral and neural level. Behaviorally, the kindergarten children indeed showed a differential pattern for overlapping and unrelated items. They responded slower to non-rhyming items that shared a phonological overlap than to phonologically unrelated items. The effect was also observed in the accuracy data, although only marginally significant. These outcomes indicate that the children have more difficulty judging phonologically related items as non-rhyming.

Even though there was no typical N450 rhyme effect for the kindergarten children, visual inspection of the data clearly showed that the ERP's elicited by the different conditions were not identical. Between 100 and $200 \mathrm{~ms}$ after stimulus onset the rhyming targets elicited a more negative response than non-rhyming targets as opposed to the $\mathrm{N} 450$ effect where the non-rhyming targets elicited a more negative response than the rhyming targets. This reversed rhyme effect was found at anterior electrodes, whereas the N450 in second graders was observed at posterior electrodes. Reports have been made of reversed rhyme effects at anterior electrodes in other rhyme studies with children and adults (Coch et al., 2005, 2002). However, a study by Khateb and colleagues (2007) which explored rhyme data by means of spatio-temporal analysis has suggested that the anterior rhyme effect and the posterior N450 effect might reflects two distinct cognitive processes (of which the functional interpretation remains unclear). Furthermore, the anterior effect in the present study has an earlier onset ( $200 \mathrm{vs.} 300 \mathrm{~ms}$ after target onset) and was less long lasting ( $400 \mathrm{vs.} 900 \mathrm{~ms}$ after target onset) than the previous findings.

In addition to the early rhyme effect, yet another ERP effect was observed in kindergartners in a later time window. From 250 to $400 \mathrm{~ms}$ the rhyming items elicited a more negative waveform than the overlapping items. The unrelated items did not differ significantly from any of the other conditions in this time window. The observed effect falls within the $200-450 \mathrm{~ms}$ time window in which we expected and observed a rhyme effect in the second grade children. However, the duration of the effect is shorter and, more importantly, the effect is reversed as opposed to the rhyme effect we observed in second graders. In kindergartners, the rhyming items are more negative than the overlapping items. This effect is more difficult to interpret. One plausible explanation could be that it reflects a developing N450. Other EEG components have been known to change during development. For example, the N1 is known to be reflected as a positive peak from the age of one to four (Kushnerenko et al., 2002). Furthermore, the semantic N400 is known to change in latency, amplitude and even scalp distribution over time (Holcomb et al., 1992). It is therefore possible that the reversed rhyme effect we observed in the $250-400 \mathrm{~ms}$ timewindow in kindergartners is a precursor of the N450 that has been observed in older children and adults (Coch et al., 2002; Grossi et al., 2001). This is further supported by the observed correlation with letter knowledge: children that have high letter knowledge show a smaller reversed rhyme effect. In other words, these children show a closer resemblance to the pattern of reading children.

As for the functional interpretation of the two early ERP effects, the findings show that on a neural level kindergarten children make a clear distinction between rhyming and non-rhyming word pairs. This finding is in correspondence with our behavioral observations that kindergartners were well able to make rhyme judgments of all three types of word pairs. So, neural rhyme effects can be measured in children that haven't started their reading education yet. More importantly, the neural findings also showed that there is a distinction between rhyming and overlapping pairs, which indicates that rhyme judgments are based on an analytical procedure and not just a global comparison of word pairs as has been suggested by Carroll and Snowling (2001). However, although the present outcomes shed more light on the development of the rhyme effect in pre-readers it is evident that follow-up research is needed to fully understand the observed rhyme effects in preliterates and especially its relation to behavioral performance.

\subsection{Additional findings}

In addition to the previously described early ERP effects, we observed a late ERP effect in both groups of children. From 550 to $750 \mathrm{~ms}$ after stimulus onset the ERP of the non-rhyming items was more positive than of the rhyming items. Since the onset of the effect lies around $500 \mathrm{~ms}$ and the distribution was centro-parietal, this effect is likely to represent a Late Positive Complex (LPC). This ERP component is thought to be involved in decisional processes (Finnigan et al., 2002; Pattamadilok et al., 2011), which explains the differences between the rhyming items (requiring a 'yes' response) and the non-rhyming items (requiring a 'no' response). A similar LPC pattern was observed a study that compared response to phonologically related (i.e., rhyming) and semantically related pairs (Perrin and Garcia-Larrea, 2003). The observed LPC was larger for (both phonologically and semantically) unrelated pairs. Although this effect does not receive much attention in the discussion of their results, it is pointed out that the changes in the LPC 
could be related to the changes in the N450 component since the components show partial overlap. For now, it remains unclear to what extends the N450 effect influences the LPC amplitude and more research is necessary to establish the functional significance of the LPC during rhyme judgment tasks.

\subsection{Limitations and suggestions for future research}

This study provides more insight in the changes that take place in the brain when a child learns how to read. Although the present data gave a clear indication that reading experience leads to changes in neural patterns, the specific interactions are not yet clear. In part, this is due to the relatively young age of the examined children. Especially in kindergarten, differences between individuals can be quite substantial. For example, some of the examined children were not able to identify a single letter whereas others were able to name all Dutch graphemes. This diversity in this specific test group leads to a noisier EEG signal, which when averaged may result in smaller or unclear observed effects. So, although the pre-readers are a very interesting group to examine, it is evident that the observed outcomes are more difficult to interpret than the effects that were found in the second graders. In future studies, it might therefore be wise to examine a larger group of prereaders which can be divided into two groups on the basis of their linguistic capacities (e.g., the amount of letter knowledge). Following this rationale, in future research we should look more closely at individual children's literacy experience. Examining early literacy skills, early reading abilities and home literacy experience would provide valuable data that can contribute to the understanding of the nature and development of (neural) rhyme processing.

One of the unexpected findings of this study was the observation that the ERP pattern in children did not show the a graded response to different types of overlap as has been found in adults (Dumay et al., 2001). As has already been noted, this could be due to an immature state of the underlying phonological representations. To further examine this, it would be interesting to examine groups of older children to see if more reading experience leads to a graded neural response that resembles an adult-like pattern. Furthermore, an alternative explanation lies in the task instruction. It may therefore be well worth to change the paradigm to a lexical decision task to examine the direct contribution of task instruction to the outcomes of the experiment. Also, it would be interesting to examine the overlapping condition in adult skilled readers to see whether the graded response is the result of more reading experience. Considering this and the observation that the children were well able to perform the task (accuracy scores are high for all condition), more difficult items could be added in the future.

Furthermore, the present data provide some insight in the processes that take place when children make a rhyme decision. One of the questions that remain is what role the syllabic structure plays in this process. Although some researchers have suggested that the phonological representations of young children are holistic in nature (Carroll and Snowling, 2001; De Cara and Goswami,
2003; Walley et al., 2003) others have found evidence that syllabic structures are available even in two-year-olds (Wijnen, 1992). Although the present findings provide some support for the idea that rhyme judging, even in kindergartners, is based on an analytical process, a more thorough examination of the role of syllabic structure in rhyme processing is essential to come to a consensus on the nature of rhyme processing.

\subsection{Implications}

The present study showed an interesting discrepancy between the neural and behavioral data. There was no evidence of a differential response to overlapping items in any of the ERP effects that were observed, whereas the behavioral data clearly showed that children processed overlapping items more slowly and less often correct than other items. Although more research is necessary to examine the development of the N450 response to overlapping items, it is important to note that measuring responses on both a behavioral and neural level provides a better insight in the rhyming skills of young children. This issue deserves special attention since rhyme judgment assessments are regularly used to examine children's level of phonological awareness both in research and practice. Therefore, this study stresses the importance of combining behavioral and neural measures to fully understand the complex processes that underlie our linguistic capabilities.

\section{Conclusions}

Although more research is needed to fully understand the underlying processes, the present study has provided more insight into the influence of reading experience on phonological awareness. The outcomes showed that rhyme performance improves with age on a behavioral level. The second graders are faster and more accurate in their responses than the kindergartners. This development in rhyme judgment can be described as the result of a maturing phonological system. The current study also showed provided insight into developmental changes on a neural level. Early readers in second grade display a neural rhyme effect that can be compared to the effects observed in older children and adults. On the contrary, kindergarten children who do not yet have reading experience show a very different ERP pattern providing neural evidence that their phonological system is still under development.

\section{Acknowledgements}

The authors would like to thank Miranda van Turennout and Doug Davidson for their help in designing the study. We are also thankful to Nina Davids and Marieke de Peuter for assisting with the data collection and Dannie van den Brink for her help in interpreting the data. And we are very grateful to all schools, teachers, parents and especially the children who all so willingly participated in this study.

\section{Appendix A}

Table A1. Dutch examples of the stimuli used in the rhyme judgment experiment. English translations are presented in parentheses.

\begin{tabular}{|c|c|c|c|c|c|c|c|c|}
\hline \multicolumn{3}{|l|}{ Rhyming pairs } & \multicolumn{3}{|c|}{ Overlapping pairs } & \multicolumn{3}{|l|}{ Unrelated pairs } \\
\hline wijn (wine) & - & pijn (pain) & pen (pen) & - & pijn (pain) & boom (tree) & - & pijn (pain) \\
\hline zoon (son) & - & boon (bean) & been (leg) & - & boon (bean) & $\operatorname{duim}($ thumb) & - & boon (bean) \\
\hline $\operatorname{kam}(c o m b)$ & - & $\operatorname{lam}(\operatorname{lamb})$ & lijm (glue) & - & $\operatorname{lam}(\operatorname{lamb})$ & neus (nose) & - & $\operatorname{lam}(\operatorname{lamb})$ \\
\hline
\end{tabular}




\section{References}

Ackerman PT, Dykman RA, Oglesby DM. Visual event-related potentials of dyslexic children to rhyming and nonrhyming stimuli. J Clin Exp Neuropsychol 1994; $16: 138-54$.

Adams M. Beginning to read: thinking and learning about print. Cambridge, MA: MIT Press; 1990

Blachmann BA. Phonological awareness. In: Kamil ML, David Pearson P, Barr R Mosenthal PB, editors. Handbook of reading research. Mahwah, NJ: Lawrence Erlbaum Associates, Inc.; 2000. p. 483-502.

Bonte M, Blomert L. Developmental changes in ERP correlates of spoken word recognition during early school years: a phonological priming study. Clin Neurophysiol 2004a;115:409-23.

Bonte ML, Blomert L. Developmental dyslexia: ERP correlates of anomalous phonological processing during spoken word recognition. Brain Res Cogn Brain Res 2004b;21:360-76.

Cardoso-Martins C. Rhyme perception: global or analytical? J Exp Child Psychol 1994;57:26-41.

Carroll JM, Snowling MJ. The effect of global similarity between stimuli on children's judgment of rime and alliteration. Appl Psycholinguist 2001;22:327-42.

Chard DJ, Dickson SV. Phonological awareness: instructional and assessment guidelines. Interv Sch Clin 1999;34:261-70.

Coch D, Maron L, Wolf M, Holcomb PJ. Word and picture processing in children: an event-related potential study. Dev Neuropsychol 2002;22:373-406.

Coch D, Grossi G, Skendzel W, Neville H. ERP nonword rhyming effects in children and adults. J Cogn Neurosci 2005;17:168-82.

Coch D, George E, Berger N. The case of letter rhyming: an ERP study. Psychophysiology 2008a;45:949-56.

Coch D, Hart T, Mitra P. Three kinds of rhymes: an ERP study. Brain Lang 2008b;104:230-43.

Coch D, Mitra P, George E, Berger E. Letters Rhyme: electrophysiological evidence from children and adults. Dev Neuropsychol 2011;36:302-18.

De Cara B, Goswami U. Phonological neighbourhood density: effects in a rhyme awareness task in five-year-old children. J Child Lang 2003;30:695-710.

Desroches AS, Newman RL, Robertson AK, Joanisse MF. Electrophysiological indices of phonological impairments in dyslexia. J Speech Lang Hear Res 2012. http:/| dx. doi.org/10.1044/1092-4388(2012/10-0351).

Dumay N, Benraiss A, Barriol B, Colin C, Radeau M, Besson M. Behavioral and electrophysiological study of phonological priming between bisyllabic spoken words. J Cogn Neurosci 2001;13:121-43.

Finnigan S, Humphreys MS, Dennis S, Geffen G. ERP ‘old/new' effects: memory strength and decisional factor(s). Psychophysiology 2002;40:2288-304.

Gratton G, Coles MG, Donchin E. A new method for off-line removal of ocular artifact. Electroencephalogr Clin Neurophysiol 1983;55:468-84

Greenhouse SW, Geisser S. On methods in the analysis of profile data. Psychometrika 1959;24:95-112.

Grossi G, Coch D, Coffey-Corina S, Holcomb PJ, Neville HJ. Phonological processing in visual rhyming: a developmental ERP study. J Cogn Neurosci 2001;13: 610-25.

Hayes RA, Slater A, Brown A. Infants' ability to categorise on the basis of rhyme. Cogn Dev 2000;15:405-19.
Hayes RA, Slater AM, Longmore CA. Rhyming abilities in 9-month-olds: the role of the vowel and coda explored. Cogn Dev 2009;24:106-12.

Holcomb PJ, Coffey SA, Neville HJ. Visual and auditory sentence processing: a developmental analysis using event-related brain potentials. Dev Neuropsychol 1992;8:203-41.

Khateb A, Pegna AJ, Landis T, Michel CM, Brunet D, Seghier ML, et al. Rhyme processing in the brain: an ERP mapping study. Int J Psychophysiol 2007;63:240-50.

Kushnerenko E, Ceponiene R, Balan P, Fellman V, Naatanen R. Maturation of the auditory change detection response in infants: a longitudinal ERP study. Neuroreport 2002;13:1843-8.

Kutas M, Hillyard SA. Reading senseless sentences: brain potentials reflect semantic incongruity. Science 1980;207:203-5.

Kutas M, Hillyard SA. Brain potentials during reading reflect word expectancy and semantic association. Nature 1984;307:161-3.

McPherson WB, Ackerman PT, Holcomb RA, Dykman RA. Event-related brain potentials elicited during phonological processing differentiate subgroups of reading disabled adolescents. Brain Lang 1998;62:163-85.

Pattamadilok C, Perre L, Ziegler JC. Beyond rhyme or reason: ERPs reveal taskspecific activation of orthography on spoken language. Brain Lang 2011;116:116-24

Perrin F, Garcia-Larrea L. Modulation of the N400 potential during auditory phonological/semantic interaction. Brain Res Cogn Brain Res 2003;17:36-47.

Praamstra P, Stegeman DF. Phonological effects on the auditory N400 event-related brain potential. Brain Res Cogn Brain Res 1993;1:73-86.

Praamstra P, Meyer AS, Levelt WJM. Neurophysiological manifestations of phonological processing: latency variation of a negative ERP component timelocked to phonological mismatch. J Cogn Neurosci 1994;6:204-19.

Radeau M, Besson M, Fonteneau E, Castro SL. Semantic, repetition and rime priming between spoken words: behavioral and electrophysiological evidence. Biol Psychol 1998;48:183-204

Rugg MD. Event-related potentials and the phonological processing of words and non-words. Neuropsychologia 1984a;22:435-43.

Rugg MD. Event-related potentials in phonological matching tasks. Brain Lang 1984b;23:225-40.

Schaerlaekens A, Kohnstamm D, Lejaegere M. Streeflijst woordenschat voor 6-jarigen in Nederland en België [Target list vocabulary for 6-year-olds in the Netherlands and Belgium]. Lisse, The Netherlands: Swets and Zeitlinger B.V.; 1999.

Snowling MJ, Hulme C. The science of reading: a handbook. Oxford, United Kingdom: Blackwell Publishers; 2005.

Verhoeven L. Screeningsinstrument voor ernstige spraak-en taalmoeilijkheden [Screening instrument for severe speech and language problems]. Arnhem, The Netherlands: CITO; 2011.

Vloedgraven JM, Verhoeven L. Screening of phonological awareness in the early elementary grades: an IRT approach. Ann Dyslexia 2007;57:33-50.

Wagensveld B, van Alphen P, Segers E, Verhoeven L. The nature of rhyme processing in preliterate children. Br J Educ Psychol 2012;82:672-89.

Walley AC, Metsala JL, Garlock VM. Spoken vocabulairy growth: its role in the development of phoneme awareness and early reading ability. Read Writ $2003 ; 16: 5-20$.

Wijnen F. Incidental word and sound errors in young speakers. J Mem Lang 1992;31:734-55. 